\title{
DEVELOPING AN ENERGY-BASED POVERTY LINE FOR SOUTH AFRICA
}

\author{
Claire Vermaak* \\ University of KwaZulu-Natal \\ vermaakc@ukzn.ac.za
}

Marcel Kohler"

University of KwaZulu-Natal

kohler@ukzn.ac.za

Received: August 2013

\author{
Bruce Rhodes+ \\ University of KwaZulu-Natal \\ rhodesb@ukzn.ac.za
}

Accepted: November 2013

\begin{abstract}
The issue of energy poverty or the lack of access to modern energy has received increasing attention in the development literature, including specific reference in the UN Millennium Development Goals (MDGs). Measures based on just energy expenditures ('energy burden') are shown to be rather inadequate when identifying energy-poor households. This paper uses an access-adjusted energy poverty measure that allows for varying energy efficiencies and access to different fuel types used by sampled households from a 2008/9 Department of Energy survey. Taking three pre-assigned thresholds of household energy use among LSMI-LSM3 households, all the South African provinces are mapped showing spatial incidences of energy poverty for electrified households. It is proposed that these access-adjusted indicators are methodologically more robust and informative for policy than conventional, purely expenditure-based indicators.
\end{abstract}

Keywords

Energy poverty; South Africa; household energy use

* Dr C Vermaak is a lecturer in the School of Accounting, Economics and Finance, University of KwaZulu-Natal, Durban, South Africa.

\# Mr M Kohler is a senior lecturer in the School of Accounting, Economics and Finance, University of KwaZulu-Natal, Durban, South Africa.

+ Dr B Rhodes is a senior lecturer in the School of Accounting, Economics and Finance, University of KwaZulu-Natal, Durban, South Africa. 


\section{BACKGROUND}

The UN Millennium Development Goal of eradicating extreme poverty by 2015 will not be met unless substantial progress is made on improving access to energy. Energy poverty or the lack of access to modern energy services is a serious obstacle to economic and social development globally and must be overcome if the eight UN Millennium Development Goals (MDGs) adopted in 2000 to fight poverty are to be achieved.

The World Bank estimates that in 2005 about 1.4 billion people were living in extreme poverty, i.e., below US\$1.25 a day, which equates to a quarter of the developing world's population. It estimates that because of the series of recent global crises, the pace of global poverty reduction slowed considerably, and by the end of 201064 million more people were expected to be living below this income threshold (World Bank, 2010).

The overall problem of 'human poverty' is a multi-dimensional issue, not just one of low income. Developing sustainable energy sources and increasing access to such energy is thought to be essential for future poverty eradication (Post-2015 Development Agenda, 2013). Access to modern forms of energy is needed to facilitate and help provide warmth, shelter, security, food preparation, cooking and storage, leading to better health, education and general well-being (Pachauri \& Spreng, 2004, Kemmler \& Spreng, 2007). The development literature makes increasing reference to energy provision and poverty eradication. Toman and Jemelkova (2003) describe how 'supply-side energy changes in less advanced countries economise on household labour, here energy availability can augment the productivity of industrial labour in the formal and informal sectors' (Toman \& Jemelkova, 2003: 8).

The link between human poverty and energy poverty was resoundingly confirmed at the World Summit on Sustainable Development in Johannesburg in 2002 with the Johannesburg Plan of Implementation (JPOI), stressing the links between energy and the MDGs (Gauteng Strategy for Sustainable Development, 2006). While the MDGs set specific targets for water, sanitation and education, there is no specific MDG that refers to energy provision explicitly. In an effort to address this omission, the recently established UN Advisory Group on Energy and Climate Change (AGECC) and the 2012 International Year for Sustainable Energy For All call on the United Nations system and its member states to commit themselves to two ambitious but achievable complementary goals: namely, ensure universal access to modern energy services by 2030; and reduce global energy intensity by $40 \%$ by 2030 . In short, eliminating energy poverty is seen by both of these initiatives to be of paramount importance in eradicating human poverty and as an essential requirement in the achievement of the other MDGs (Advisory Group on Energy and Climate Change, 2010). It is acknowledged that enormous welfare benefits follow once people have access to light, power, heat, irrigation and cleaner air (Sustainable Energy For All, 2012), yet it is estimated by the International Energy Agency (IEA) and AGECC that between $\$ 35 \mathrm{bn}$ to $\$ 40 \mathrm{bn}$ will need to be spent per annum to achieve the 2030 goal (Practical Action, 2012).

\section{SOUTH AFRICA AND ENERGY POVERTY}

South Africa is one of few countries in Sub-Saharan Africa that has made great strides in addressing the provision of energy services. Part of the strategic objectives and targets of its Medium Term Strategic Framework is to, 'include, amongst others, diversification of the energy mix in pursuit of renewable energy alternatives and the promotion of energy efficiency' (The 
Presidency, 2009). Government is of the view that energy poverty deepens general poverty and contributes to handicaps, such as poor health and education. Its position is clarified in the Energy White Paper (Department of Minerals and Energy (DME), 1998), where it is stated that, 'energy security for low-income households can help reduce poverty, increase livelihoods and improve living standards' (DME, 1998:ix).

Statistics SA (2008) showed that 2.5 million South African households were not connected to the electricity grid and most were in the country's rural areas. Furthermore, it was reported that $70 \%$ of rural households still rely to some extent on wood fuel and paraffin, and this is in spite of some having electricity connections (Statistics South Africa, 2008). The South African government has introduced a number of national programmes to achieve the universal access to electricity by 2014 . These include, among others, the Integrated National Electrification Programme (INEP), which provides a socio-economic support net that ensures that previously unconnected households have access to electricity. According to the Department of Energy sponsored Socio-Economic Impact of Electrification Survey (2009), the INEP has been able to connect 4.9 million households over the past 15 years, with $75 \%$ of $($ or $9,245,357)$ households in South Africa having access to electricity. At a provincial level, KwaZulu-Natal and the Eastern Cape remain the least electrified provinces; with $34 \%$ and $40 \%$ of households in these provinces, respectively, remaining un-electrified. Electrification backlogs in these two provinces are also among the highest in the country.

\section{MEASURING ENERGY POVERTY}

Energy poverty is best viewed as a diverse set of symptoms rather than a singularly defined issue. The cause of energy poverty varies by region but the effects of zero electricity are common to all. Unfortunately, electricity is only one part of the problem. Access to efficient and affordable cooking and heating fuels, such as liquefied petroleum gas (LPG) or kerosene, are equally, if not more, vital to alleviating the effects of energy poverty. Broadly defined, energy poverty is viewed as the lack of access to modern energy services, be they electricity, heating or cooking fuels, necessary for human development. Unfortunately there is a lack of consensus internationally on what the term 'energy access' means.

In its World Energy Outlook 2009, the IEA identified three levels of access to energy services depending on household energy needs and the benefits energy services provide. These are illustrated below and include:

level 1: the minimum level of energy access required by households to satisfy basic human needs,

level 2: the energy access required by households to improve productivity, and

level 3: the level of energy access required by households to satisfy modern society needs. 
Incremental levels of access to energy services

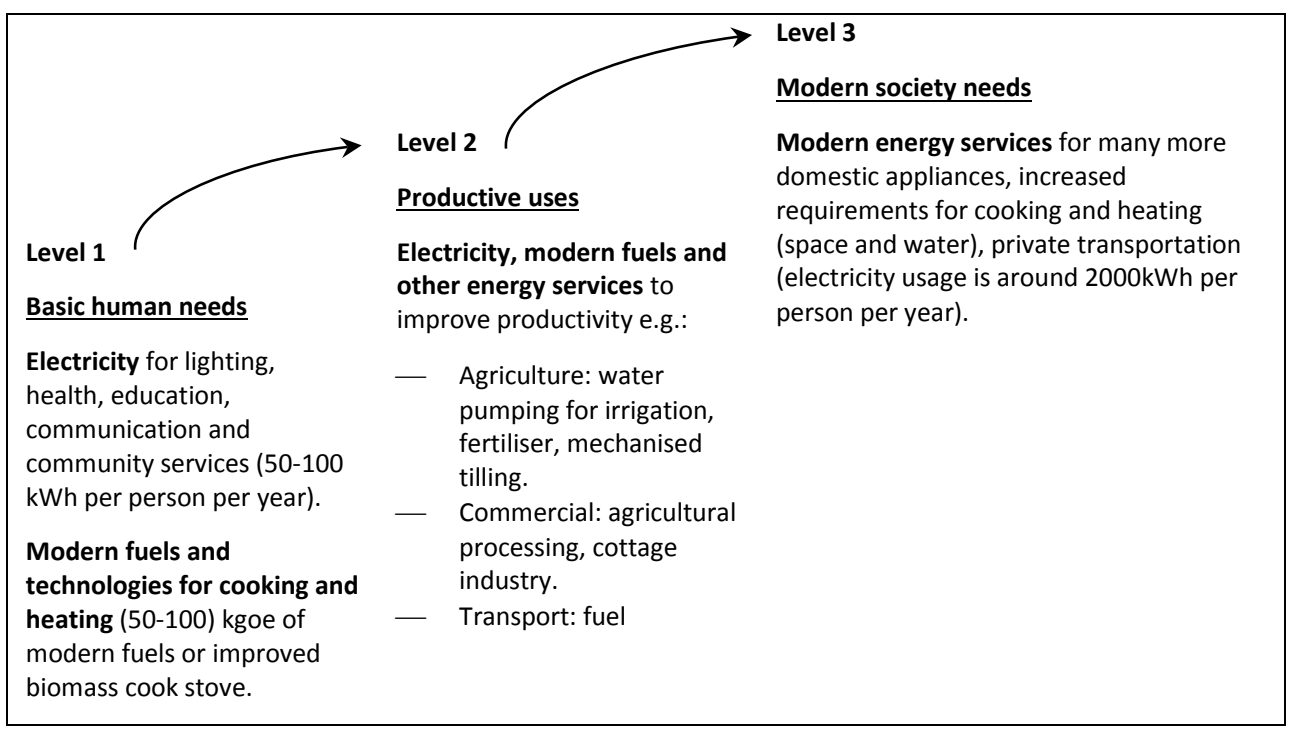

Source: IEA, 2009

The literature has traditionally been dominated by a theory of transition in which households gradually ascend an 'energy ladder' in a similar manner as shown above. The ladder, beginning with traditional biomass fuels (firewood and charcoal), moves through to transition fuels (kerosene, coal and charcoal) and then on to modern commercial fuels (LPG, natural gas, or electricity) as incomes rise and urbanisation grows.

It is clear that people demand more energy as their incomes rise and that increased use of modern energy by households is a key element in the broader process of human development, but the shift from traditional to modern energy sources is not a smooth one. Empirical work by the Energy Sector Management Assistance Programme (2000), IEA (2002) and Heltberg (2003), and also research on energy use patterns in South Africa by Aitken (2007), has revealed fairly consistently that poor households tend to rely on multiple energy sources for their energy needs and this applies to both electrified and non-electrified households. This finding provides a strong empirical challenge to prevailing energy transition theories and the 'energy ladder' model. There are several possible explanations for this. One is that unreliable supplies require households to rely on diverse sources of energy. Another is that different energy sources are more cost-effective in some uses than in others. For instance it may make economic sense to use electricity for lighting but LPG for cooking.

'Fuel poverty' is a related but distinct concept where users of energy have access to, but cannot afford, the energy they require. In terms of quantifying fuel poverty, a common indicator used in country studies is the 'energy burden' of households within a region. This is based on the notion that poor households spend a greater proportion of their income on energy than their more wealthy household counterparts. It is calculated as the share of total household income or expenditure devoted to energy. The South African Department of Energy is consistent with the general literature in deciding that a household is deemed fuel-poor if it spends between 10 and $15 \%$ of its income on domestic energy needs, with $10 \%$ being the norm (Department of Energy, 2009,2010 ). Households with energy expenditures above this threshold are considered energy- 
poor, and are likely to be confronted with difficult choices between meeting energy requirements and spending on competing goods.

According to Aitken (2007), the energy burden for South African households can amount to between 12 and $20 \%$. To put this in perspective: this is the equivalent of a middle-income household earning R20 000 a month and spending up to R4 000 a month on acquiring energy services. The Department of Energy (2009) estimates that the incidence of fuel poverty among electrified households is highest in the Eastern Cape at $31 \%$, with a further $54 \%$ spread across KwaZulu-Natal, Limpopo, Mpumalanga and Gauteng. Non-electrified households exhibit a relatively similar pattern, with large energy poverty shares accounted for by households in the Eastern Cape, KwaZulu-Natal and rural areas.

The quantification and assessment of energy poverty as simple fuel poverty, based solely on household energy burdens (expenditures), is problematic to say the least. Poor households in countries such as South Africa typically rely on cheap but inferior biomass for their energy needs. As a result fuel poverty measures would completely underestimate the extent of energy poverty in both the country and its provinces. Consider what is meant when we use the term 'energy-poor'. If households A and B both spend $15 \%$ of their income on energy, both are classified as equally poor according to the Department of Energy and its fuel poverty (or energy burden) measure. However, if $A$ buys paraffin and candles, while B buys electricity, then household B obtains a greater quantity of useful energy, since electricity is a more efficient energy source. Household A should thus be classified as poorer than B, by taking into account the quantity of energy used by the household, rather than just its cost. Additionally, if household $B$ now gains access to free basic electricity ( $F B E$ ), we argue that it should be classified as less poor than it was before, but its poverty status would not change if only its energy burden is taken into account.

Recent literature has covered a number of issues regarding the definition of energy poverty and energy access. The Multidimensional Energy Poverty Index (MEPI) is designed to capture energy deprivations experienced by a person using a basket of five dimensions: cooking, lighting, telecommunications and services of appliances for general household use and education/entertainment (Nussbaumer et al., 2012). Someone is energy-poor if the combination of the experienced deprivations exceeds some pre-defined threshold. The actual MEPI is given as a headcount ratio calculated as the proportion of energy poor to the average intensity of deprivation of the energy poor. While acknowledging diverse requirements at the local level, the content of the basket is largely concurred with by Pachauri (2011), although thermal comfort is also mentioned as an energy poverty dimension.

In order for the international community and donors alike to increase effective activity and seriously tackle energy poverty, global targets and universally agreed dimensions need to be established as well as the recognition of minimum energy needs, which can vary considerably across age, gender, social customs, climate and culture (Bazilian et al., 2010; Pachauri, 2011). Defining basic needs to include in the energy basket, identifying minimum useful energy services thresholds to set as benchmarks for progress, and identifying the costs of current and new energy carrier technologies is essential when operationalising a definition of energy access (Pachauri, 2011).

In addition to the need for clear definitions of energy poverty and access, recognition of the grassroots issues is also needed for effective policy. The poorest households may struggle to make the effort to try a new fuel or stove simply because the struggle of day-to-day living consumes all available effort. Issues in male-dominated households, where there is a reluctance 
to let women try anything new and not reorganise household central practices in order to use new technologies, may severely hamper successful energy poverty eradication policy (Pachauri \& Spreng, 2011). Provision alone is not a necessary condition for use, let alone sustained use. Indicators of progress in the energy poverty access nexus are just as important as predefined energy thresholds and basket-of-needs definitions (Pachauri \& Spreng, 2011).

Against this literature backdrop we focus on defining energy poverty in terms of access to energy services as well as describe how access to such services is related to an improvement in household well-being. The consideration of access is an important complement to a consumption-based measure of energy poverty, because what distinguishes a poor household from a wealthy one is also the wider range of choice in which fuels to use (more efficient, more convenient, less polluting) and which equipment and appliances to buy.

These considerations formed the basis of the development of a set of energy quantity or energy unit-based measures of energy poverty for South Africa, and are discussed in detail in a study by Vermaak, Kohler and Rhodes (2009). For the sake of completeness, the salient features of this methodology are repeated in the discussion below.

\section{DATA AND METHODOLOGY}

The data is drawn from the 2008/2009 Department of Energy (Department of Energy, 2009) survey on the socioeconomic impact of electrification, a survey of 3960 households from all nine of South Africa's provinces. The sample consists of both electrified and non-electrified households in Living Standards Measure (LSM) groups 1-3, corresponding to household incomes of less than R1600 per month. The sample was drawn on enumerator areas ( $E A s)$ and stratified on province, with 50 EAs sampled per province and 9 households per $\varepsilon A$. The sample was selected so that two-thirds of households are electrified and the remainder non-electrified. While this ratio is not proportionally representative of households, the sample contains weights that are used throughout the analysis to make the results of the estimation nationally representative of the total population of LSMI - LSM3 households. The survey records spending by the household on the following energy types: paraffin, gas, candles, coal, firewood, solar, electricity, batteries, car batteries, generators and other energy. All of these energy sources are included in this study. The dataset also contains an indicator for whether the household receives free basic electricity (FBE).

A small proportion of households do not report any expenditure on energy. This may arise if households collect or use their own fuel sources (such as firewood, dung, bagasse, etc.). It does not imply that the household did not consume any energy, since the survey records the purchase rather than the use of energy. Thirty-two households do not purchase any energy, but collect their own firewood (however, the survey does not record the quantity of firewood collected). Ten households do not purchase any energy, but receive $F B E$. The analysis in this study is thus conditional on a household having purchased some form of energy, or receiving $F B E$, which restricts the sample to 3893 households.

The energy unit measures of poverty that are advanced in our study recognise the inadequacy of measuring energy poverty by simply focusing on the issue of fuel poverty or the energy burdens of households. Our measure takes both access and affordability issues relating to household energy needs into account. We quantify in energy units (namely, kilowatt hours) the amount of useful energy households require in order to meet specific consumption requirements. 
In determining this requirement we use three pre-existing annual per capita useful energy access thresholds: These are as follows:

- $667 \mathrm{kWh}$, which represents the energy equivalent of the United Nation's $\$ 1.25$ per person per day (or 'extreme' income-based) poverty line. In the sample $33 \%$ of individuals live in households with per capita income below $\$ 1.25$, and $33 \%$ of individuals live in households with access-adjusted useful per capita energy consumption below $667 \mathrm{Kwh}$.

- $1200 \mathrm{kWh}$, which represents the IEA's minimum level of energy access required for households to satisfy basic human needs; and

- $2000 \mathrm{kWh}$, which represents the IEA's level of energy access for households to satisfy modern society needs.

We calculate and map the percentage of households below each of these three energy thresholds according to our access-adjusted indicator. To reach this indicator, a single price-to-kWh conversion factor per fuel type is used nationally to convert all energy expenditures by households into energy use figures (TABLE l).

\section{TABLE 1: Price to kWh conversion factors for each energy carrier}

\begin{tabular}{|c|c|}
\hline Energy carrier & Conversion factor (c/kWh) \\
\hline Paraffin & 66 \\
\hline Gas & 71 \\
\hline Candles & 32 \\
\hline Coal & 14 \\
\hline Wood & 15 \\
\hline Solar & 179 \\
\hline Electricity & 43 \\
\hline Batteries & 22 \\
\hline Diesel & 65 \\
\hline Bagasse & 7 \\
\hline Biomass (solid) & 101 \\
\hline Wind (onshore) & 107 \\
\hline
\end{tabular}

Source: Authors' calculations based on DME (1998) and IEA (2002) data. Diesel is used as the conversion factor for generators and bagasse for "other energy".

Where households report they receive FBE, it is assumed that all $50 \mathrm{kWh}$ allocated per month is used. Actual (raw) energy quantities/units are then converted into 'useful energy', using efficiency factors for each fuel type (Winkler, 2006). The energy efficiency factors for cooking have been used for all fuel types except in the case of candles, where the efficiency factor used is for lighting (TABLE 2). For most fuel sources, the efficiency for cooking is greater than for other applications, especially for lighting. Therefore our estimates of useful energy are likely to 
overstate somewhat the true quantity of energy that households obtain from their energy spending.

TABLE 2: عfficiency conversion factors for each energy carrier

\begin{tabular}{lc}
\hline Energy carrier & Efficiency factor \\
\hline Paraffin & 0.42 \\
Gas & 0.55 \\
Candles & 0.0005 \\
Coal & 0.13 \\
Wood & 0.25 \\
Solar & 1 \\
\hline Electricity & 0.65 \\
Batteries & 0.65 \\
Carbatteries & 0.9 \\
\hline Other energy & 0.25 \\
\hline Generators & 0.42 \\
\hline
\end{tabular}

Source: Winkler (2006:127). Since the survey does not record how much of each energy type has been used for each purpose, all conversion factors used here are for cooking, except for candles (lighting) and batteries (appliances)

The access-adjusted measure is estimated by weighting the energy used by the household according to the accessibility of its source (TABLE 3 ). The greater the accessibility of the energy source, the higher the weighting it receives. That is, the traditional sources receive a weighting of one as a baseline; transitional sources receive a weighting of two, and modern sources receive a weighing (the highest) of three. Implicit here is the assumption that modern sources are three times more accessible than traditional fuel types.

TABLE 3: Definitions of energy sources

\begin{tabular}{ll}
\hline Traditional & firewood, candles, other energy \\
\hline Transitional & gas, paraffin, coal, batteries, car batteries \\
Modern & electricity, generators, solar \\
\hline
\end{tabular}

Source: Authors' definitions, based on Kemmler and Spreng (2007)

In the absence of any guidance from the data, there is a degree of arbitrariness in the choice of the accessibility weighting scheme. However, the methodology described above was developed by Kemmler and Spreng (2007), based on Pachauri and Spreng (2004), who found that the weighting was robust for Indian data. The method was applied to South African Income and Expenditure Survey data by Vermaak et al. (2009), who conducted considerable sensitivity analysis regarding the accessibility weighting scheme as well as the other assumptions made during the course of the analysis. The estimation of energy poverty was found to be robust to 
these assumptions, establishing confidence that this methodology can be reliably applied to South African household survey data (Vermaak et al., 2009).

This access-adjusted useful energy unit measure is applied to the data set in quantifying the incidence of energy poverty in South Africa. That is, for a given energy poverty line, the proportion of households below that line is identified. This is done for each province in South Africa and is displayed on a series of greyscale-coded GIS maps per energy poverty line. This gives an instant visual assessment of where energy poverty is at its highest in South Africa, thereby prioritising areas for electrification, renewable energy provision or similar. For the sake of brevity only maps for electrified households are shown.

\section{ENERGY BURDEN AND ACCESS-ADJUSTED ENERGY POVERTY RESULTS}

All results below are disaggregated by the nine provinces of South Africa and represent the total population of LSMI - LSM3 households. We begin by showing the incidence of 'fuel poverty' among South African households (TABLE 4). This is measured by examining the energy burden of households, which is calculated as households' energy expenditures as a percentage of total monthly income. Recall that this is the measure used by the South African Department of Energy to measure energy poverty.

\subsection{Energy burden results}

TABLE 4: Energy expenditure as a percentage of total monthly household income, by province

\begin{tabular}{lcc}
\hline Province & Electrified & Non-Electrified \\
\hline Eastern Cape & 20.759 & 23.249 \\
\hline Free State & 14.688 & 13.484 \\
Gauteng & 18.254 & 33.795 \\
\hline KwaZulu-Natal & 15.627 & 15.603 \\
Limpopo & 11.747 & 15.951 \\
\hline Mpumalanga & 17.881 & 15.486 \\
North West & 16.120 & 22.552 \\
\hline Northern Cape & 11.775 & 11.625 \\
Western Cape & 16.781 & 22.045 \\
\hline
\end{tabular}

Source: Authors'calculations

TABLE 4 shows that Gauteng's non-electrified households spent the largest share of their income on energy at just under $34 \%$. Electrified households in the Northern Cape and Limpopo provinces spent the smallest percentage of their total monthly income on energy at just under $12 \%$. Recall earlier that the threshold for determining fuel poverty is between 10 and $15 \%$ of income spent on domestic energy needs, with $10 \%$ being the norm (Department of Energy, 2009; 2010). Households with energy expenditure above this threshold are considered energy-poor by the South African authorities. 
GIS Map 1 displays the data from TABLE 4. This will serve as a useful visual comparison to later tables and maps that use our access-adjusted or energy-unit poverty indicator described earlier.

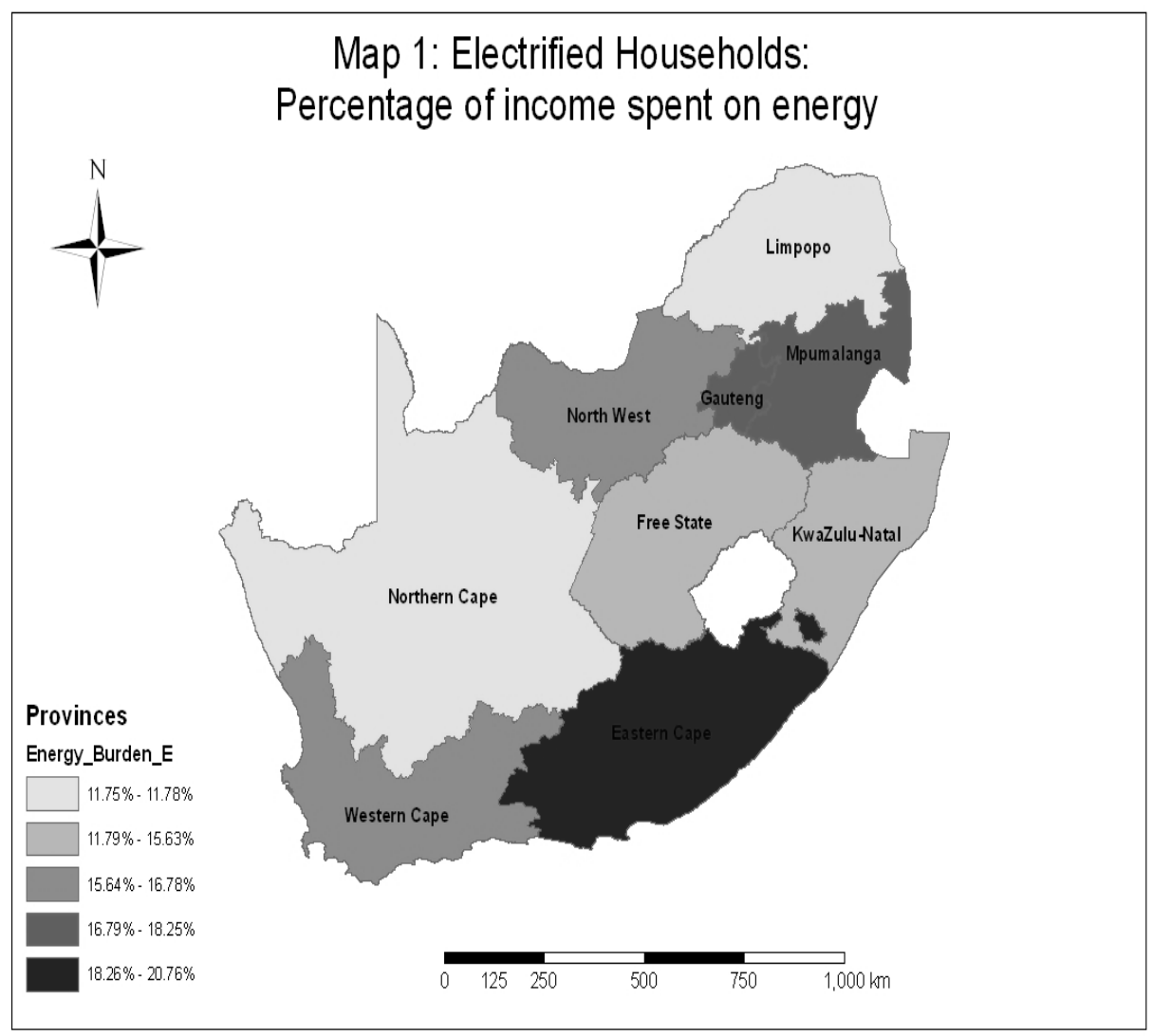

Source: Authors'calculations

All the maps in this report show increasing percentages (increasing energy poverty) as we move from lighter to darker greyscale. In Map 1 the darker shade indicates increasing fuel poverty. The darkest grey zone (just the Eastern Cape in Map 1) shows an area with the highest incidence of energy poverty, which in this case is measured by percentage of income spent on fuel. The Northern Cape and Limpopo are the least fuel-poor; Eastern Cape, Gauteng and Mpumalanga are the most fuel-poor.

\subsection{Access-adjusted energy poverty results}

The results from the access-adjusted measure of energy poverty for electrified households will be shown in Maps 2 to 4 . Based on the efficiencies of different fuels and the chosen weighting system for access, the percentages of households below $667 \mathrm{kWh}, 1200 \mathrm{kWh}$ and $2000 \mathrm{kWh}$ per capita per annum are calculated. These series of energy poverty results are shown all together in TABLE 5. 
TABLE 5: Percentage of households below different energy poverty lines, by province

\begin{tabular}{lcccccc}
\hline & \multicolumn{2}{c}{$\begin{array}{c}\text { S1.25 equiv } \\
\text { (667kWh) }\end{array}$} & \multicolumn{2}{c}{$\begin{array}{c}\text { Basic needs } \\
\text { (1200kWh) }\end{array}$} & \multicolumn{2}{c}{$\begin{array}{c}\text { Modern needs } \\
\text { (2000kWh) }\end{array}$} \\
& $\varepsilon$ & $N \varepsilon$ & $\varepsilon$ & $N \varepsilon$ & $\varepsilon$ & $N \varepsilon$ \\
\hline Eastern Cape & 20.6 & 41.2 & 40.1 & 65.6 & 62.7 & 81.5 \\
Free State & 15.4 & 67.1 & 28.1 & 85.7 & 60.0 & 94.8 \\
Gauteng & 6.1 & 27.5 & 20.5 & 53.3 & 49.7 & 76.2 \\
KwaZulu-Natal & 9.8 & 69.7 & 35.5 & 80.2 & 56.7 & 88.6 \\
Limpopo & 41.2 & 61.6 & 65.9 & 74.3 & 82.1 & 86.0 \\
Mpumalanga & 23.4 & 57.1 & 42.8 & 74.7 & 66.5 & 84.5 \\
North West & 17.3 & 52.8 & 31.9 & 72.5 & 57.7 & 82.4 \\
Northern Cape & 21.4 & 64.0 & 52.5 & 79.6 & 78.5 & 90.3 \\
Western Cape & 4.0 & 25.7 & 20.2 & 46.6 & 49.7 & 61.1 \\
\hline
\end{tabular}

Source: Authors'calculations

For example, TABLE 5 tells us that $20.6 \%$ of electrified $(\varepsilon)$ households in the Eastern Cape have access to $667 \mathrm{kWh}$ or less per person per year, or $41.2 \%$ for non-electrified (NE) households. As expected, for each province and at every poverty threshold, non-electrified households are more energy-poor than electrified households. For most provinces, the differences in poverty rates between electrified and non-electrified households are quite severe. In KZN, less than $10 \%$ of electrified households are below the $\$ 1.25$ equivalent line of $667 \mathrm{kWh}$, in sharp contrast to the non-electrified households where nearly $70 \%$ are below this same line. In other provinces, most notably Limpopo but also Mpumalanga, the difference is less severe, but non-electrified households are nonetheless poorer. The energy poverty percentage calculated using the accessadjusted measure increases substantially as the energy poverty threshold rises. For instance, at the 'modern needs' poverty line, at least half of all LSMI - LSM3 households are energy-poor, regardless of whether or not they are electrified.

The results in TABLE 5 are quite different from those observed in TABLE 4 regardless of the energy access threshold used. For instance, the fuel poverty measure shows the Northern Cape and Limpopo as not particularly vulnerable (supported by lighter shades in Map 1). However, when factoring in the type of fuels used and corresponding access adjustments into our energy poverty measures as used to calculate $\operatorname{TABL} \varepsilon 5$, both these provinces appear considerably energy-poor (darker shading, e.g., map 2). In contrast, the Western Cape and Gauteng are among the best performers by the access-adjusted measure of poverty yet a different conclusion is gathered by the energy burden expenditure figures.

Maps 2 to 4 below (author calculations) show the GIS equivalent of the TABLE 5 results for electrified households only. It is the position of this paper that the following maps are more revealing and accurate in the assessment of energy poverty across South Africa, than the energy burden measure. 

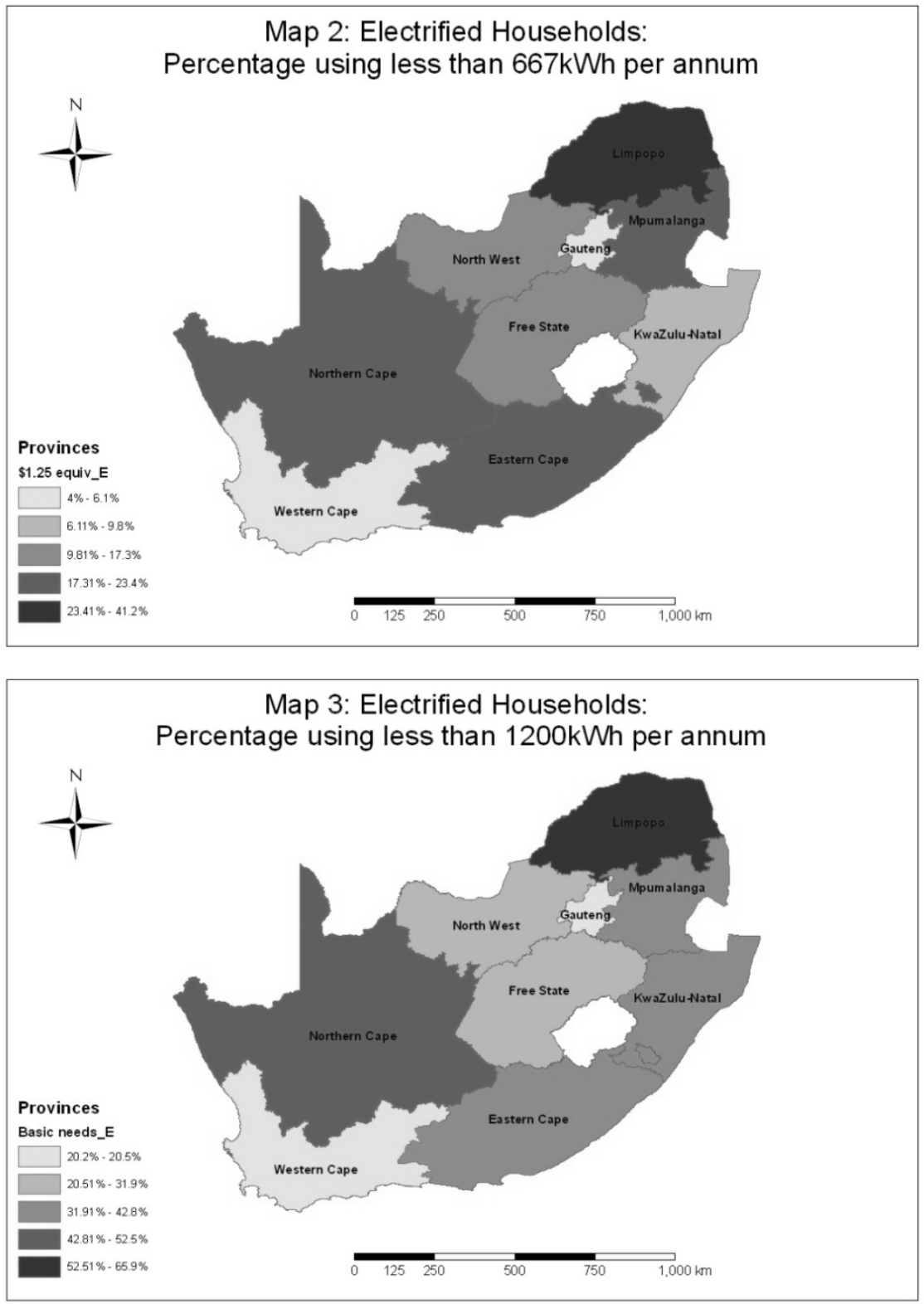


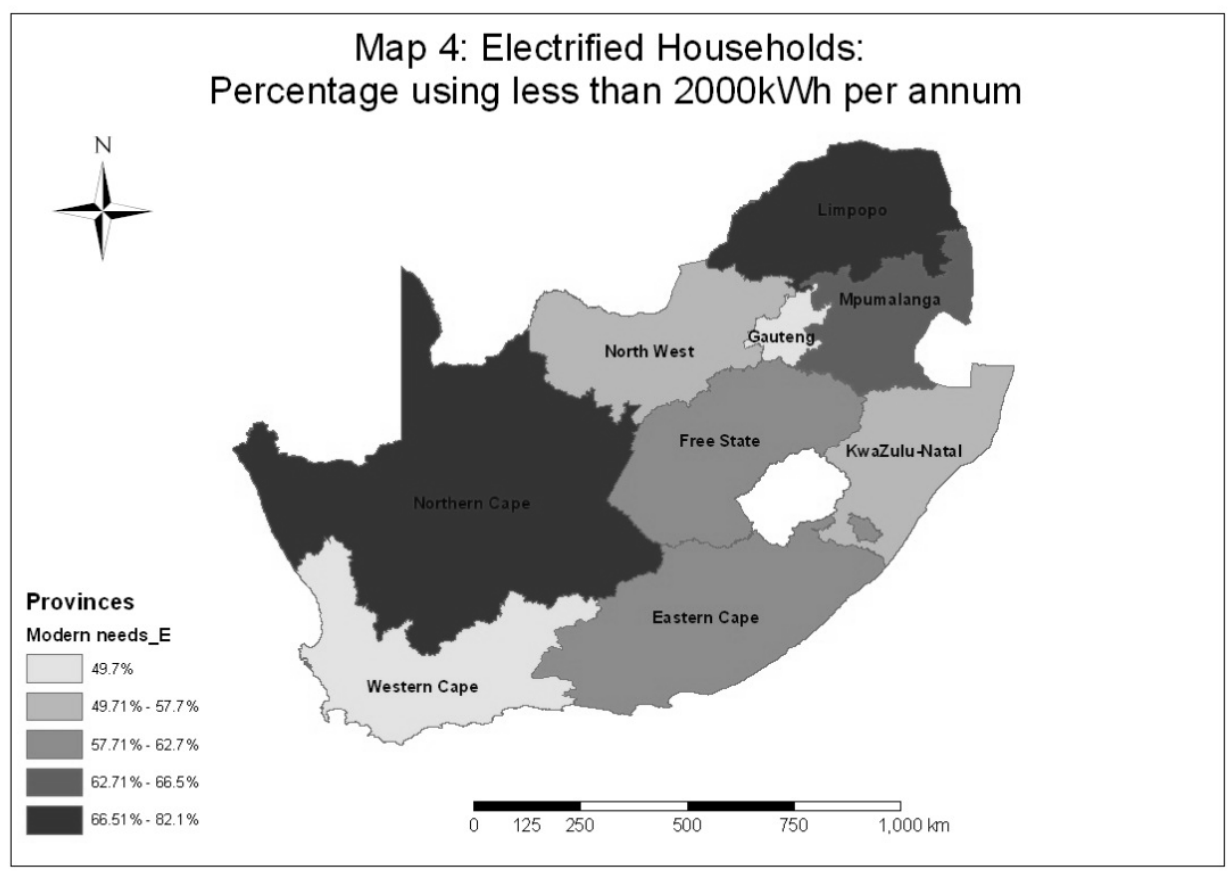

Source: Authors'calculations

As mentioned earlier, maps 2 to 4 show that for electrified households the Western Cape and Gauteng province are generally the least energy-impoverished (lightest shading), and both these provinces generally show the lowest percentages of households below the chosen energypoverty threshold. Conversely, the Northern Cape, Limpopo and the Free State appear vulnerable to energy poverty (darker shading). The non-electrified data also showed similar results to maps 2 to 4 .

\section{CONSUMPTION CONCENTRATION INDEX}

TABLE 6 below captures the extent to which households have to rely on a diversity of fuels. This is calculated as the sum of the squares of the shares of different energy sources in a household's energy consumption. The maximum value is one (when a household uses only one fuel source), while the lower the value the greater the fuel diversity. It is worth noting here that a score of one may mean that only electricity is used (thereby showing energy 'wealth') yet by the same logic a score of one could indicate significant energy poverty (only using wood for cooking, heating, lighting). Map 5 shows this data for all households. 
TABLE 6: Consumption of Energy Concentration Index

\begin{tabular}{lccc}
\hline & All & Electrified & Non-electrified \\
\hline EC & 0.255 & 0.400 & 0.329 \\
FS & 0.287 & 0.538 & 0.504 \\
GP & 0.259 & 0.502 & 0.250 \\
KZN & 0.231 & 0.597 & 0.216 \\
LP & 0.377 & 0.411 & 0.427 \\
MP & 0.253 & 0.298 & 0.230 \\
NW & 0.277 & 0.342 & 0.324 \\
NC & 0.547 & 0.627 & 0.222 \\
WC & 0.423 & 0.694 & 0.351 \\
\hline
\end{tabular}

Source: Authors'calculations

Map 5 below shows distribution of the consumption concentration by province.

Map 5: Energy Consumption Concentration Index for all fuel types
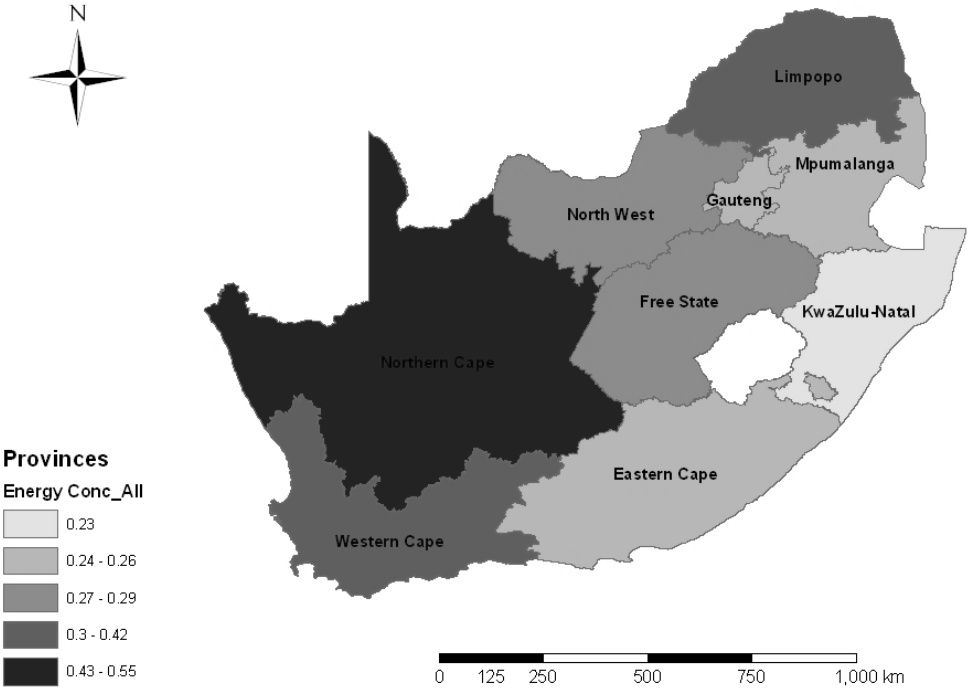

Source: Authors'calculations

It is interesting to note that the Western Cape, Limpopo and the Northern Cape score a high index (indicating a tendency to use one source). Taken in isolation this is not very informative, but when viewed with maps 2-4 we can see that the Western Cape is characterised by single-source energy wealth, i.e., mainly provided by electricity, whereas the Northern Cape is characterised by also using a single source, but a rather inefficient one in terms of kWh output, such as wood perhaps. 


\section{CONCLUSION AND POLICY IMPLICATIONS}

In order to alleviate energy poverty, it is critical that we are first able to identify accurately which households (and municipalities) are poor, and which are not. We therefore recommend that if the Socio-economic Impact of Electrification Survey is to become an annual panel study future rounds of the survey should collect information on the prices that households pay for their individual energy sources, in addition to the total cost. This will enable researchers to calculate more accurately the quantity of energy used, and thus to identify more precisely the degree of energy poverty experienced by households.

It is clear that conventional energy burden calculations showing energy poverty by expenditure, as reported in the Department of Energy (2009) study, are very different to the access-adjusted (energy-unit) -based indicators of energy poverty reported in this study. It is our contention that access-adjusted-based indicators of energy poverty are more informative and accurate. In the case of South Africa, we identify energy poverty rates among electrified households to be highest in the Limpopo province (66\%), followed by the Northern Cape (53\%), Mpumalanga (43\%), Eastern Cape (40\%), KwaZulu-Natal (36\%), North West (32\%), and Free State (28\%), and lowest in Gauteng (21\%) and the Western Cape (20\%). In the case of non-electrified households we find energy poverty rates to be highest in the case of the Free State $(86 \%)$ and lowest in the Western Cape $(47 \%)$. Interestingly, these results are significantly different from those shown by the South African Department of Energy.

If we accept the validity of the access-adjusted (energy-unit) measure, the maps presented above reveal invaluable insights into where energy access needs to be developed. These areas should be targeted by regional and national policies to maximise returns from expensive energygeneration investment.

In general we find that energy poverty is widespread among LSMI - LSM3 households, and is especially severe among households that lack access to modern energy sources, such as electricity. The expansion of access to such modern energy sources is thus one of the keys to reducing energy poverty. This will enable households not only to reduce their reliance on unsafe, dirty sources of energy, but also to increase the quantity of energy that they obtain per Rand spent, by using more efficient energy sources. We therefore recommend, in general, that the expansion of access to electricity be continued.

Given that many of the poorest households are located in remote rural areas, expansion of access to the electricity grid may be prohibitively expensive. We recommend, in such cases, that access to renewable energy sources, such as solar and wind power, be expanded. Such energy sources can be located close to the areas that are the most energy-poor, and may therefore prove more cost-effective than connection to the state's electricity grid. Further research into the cost-effectiveness of small-scale renewable energy projects is highly recommended. Finally, we recommend that the expansion of access to renewable energy be accompanied by an education programme, so that households do not view alternative energy sources as being inferior to electricity. 


\section{LIST OF REFERENCES}

Advisory Group on Energy and Climate Change (2010). Energy for a Sustainable Future. The SecretaryGeneral's Advisory Group on Energy and Climate Change: Summary Report and Recommendations, 28 April 2010, New York. New York: United Nations.

Aitken, R. (2007). Household energy use: a comparison of household energy consumption and expenditure across three provinces. Journal of Energy in Southern Africa, 18(1), pp. 20-28.

Bazilian, M., Nussbaumer, P., Cabraal, A., Centurelli, R., Detchon, R., Gielen, D., Rogner, H., Howells, M., McMahon, H., Modi, V., Nakicenovic, N., O'Gallachoir, B., Radka, M., Rijal, K., Takada, M. \& Ziegler, F. (2010). Measuring Energy Access: Supporting a Global Target. The Earth Institute, Columbia University, New York.

Department of Energy (2009). Socio-Economic Impact of Electrification: Household Perspective 2009. Pretoria, South Africa: Department of Energy.

Department of Energy (2010). Draft Integrated Resource Plan 2010. Pretoria, South Africa:

Department of Energy.

Department of Minerals and Energy (DME). (1998). White Paper on the Energy Policy of the Republic of South Africa. Pretoria: Department of Minerals and Energy.

Energy Sector Management Assistance Programme (2000). Energy Services for the World's Poor. World Bank/ESMAP Energy and Development Report. Washington, D.C.: World Bank.

Gauteng Strategy for Sustainable Development. (2006). Gauteng Strategy for Sustainable Development: State of Play Report. [Online] Available:

http://www.gdace.gpg.gov.za/html/GSSDStatel5May06.pdf. (Accessed 27 August 2008).

Heltberg, R. (2003). Household Fuel and Energy Use in Developing Countries - A Multi-country Study. Washington, D.C.: World Bank.

International Energy Agency (IEA) (2002). World Energy Outlook 2002. Paris: International Energy Agency.

International Energy Agency (IEA) (2009). World Energy Outlook 2009. Paris: International Energy Agency.

Kemmler, A. \& Spreng, D. (2007). Energy indicators for tracking sustainability in developing countries. Energy Policy, 35, pp. 2466-2480.

Nussbaumer, P., Bazilian, M., Modi, V. \& Yumkella, K. (2012). Measuring energy poverty: Focusing on what matters. Renewable and Sustainable Energy Reviews, 16, pp. 231-243.

Pachauri, S. \& Spreng, D. (2004). Energy use and energy access in relation to poverty. Economic and Political Weekly, 39(3), pp. 271-278.

Pachauri, S. (2011). Reaching an international consensus on defining modern energy access. Current Opinion in Environmental Sustainability, 3, pp.235-240.

Pachauri, S. \& Spreng, D. (2011). Measuring and monitoring energy poverty. Energy Policy, 39, pp.7497-7504.

Practical Action. (2012). Poor People's Energy Outlook. Rugby, U.K.: Practical Action. 
Post-2015 Development Agenda. (2013). A New Global Partnership: Eradicate Poverty and Transform Economies Through Sustainable Development. The Report of the High-Level Panel of Eminent Persons on the Post-2015 Development Agenda. New York. United Nations.

Statistics South Africa (2008). General Household Survey 2007. Pretoria: Statistics South Africa.

Sustainable Energy for All. (2012). Technical Report of Task Force 1. New York: United Nations.

The Presidency (South Africa). (2009). Together Doing More and Better: Medium Term Strategic Framework: A Framework to Guide Government's Programme in the Electoral Mandate Period (20092014). Pretoria: Minister in the Presidency: Planning.

Toman, M. \& Jemelkova, B. (2003). Energy and Economic Development: An Assessment of the State of Knowledge. Washington, D.C.: Resources for the Future (Discussion paper 03-13).

Vermaak, C., Kohler, M. \& Rhodes, B. (2009). Developing energy based poverty indicators for South Africa. Journal of Interdisciplinary Economics, 21, pp.163-195.

Winkler, H. (2006). Energy Policies for Sustainable Development in South Africa-Options for the Future. Energy Research Centre, University of Cape Town.

World Bank. (2010). World Development Report 2010. Washington, D.C.: World Bank.

World Summit on Sustainable Development. (2003). Johannesburg Plan of Implementation (JPOI), World Summit on Sustainable Development, Johannesburg, South Africa, 26 August - 4 September 2002. 
Vermaak, Kohler \& Rhodes 